\title{
Properties of Metallic and Oxide Thin Films Based on Ti and Co Prepared by Magnetron Sputtering from Sintered Targets with Different Co-Content
}

\author{
Damian Wojcieszak ${ }^{1}$ (D), Michał Mazur ${ }^{1}{ }^{(\mathbb{D}}$, Patrycja Pokora ${ }^{1}{ }^{*}$, Adriana Wrona ${ }^{2}$ (D) Katarzyna Bilewska ${ }^{2}$, \\ Wojciech Kijaszek ${ }^{1}$, Tomasz Kotwica ${ }^{1}$, Witold Posadowski ${ }^{1}$ and Jarosław Domaradzki $^{1}$ \\ 1 Faculty of Microsystem Electronics and Photonics, Wroclaw University of Science and Technology, \\ Janiszewskiego 11/17, 50-372 Wroclaw, Poland; damian.wojcieszak@pwr.edu.pl (D.W.); \\ michal.mazur@pwr.edu.pl (M.M.); wojciech.kijaszek@pwr.edu.pl (W.K.); tomasz.kotwica@pwr.edu.pl (T.K.); \\ witold.posadowski@pwr.edu.pl (W.P.); jaroslaw.domaradzki@pwr.edu.pl (J.D.) \\ 2 Lukasiewicz Research Network-Institute of Non-Ferrous Metals, Gliwice Division, Sowinskiego 5, \\ 44-100 Gliwice, Poland; adriana.wrona@imn.lukasiewicz.gov.pl (A.W.); \\ katarzyna.bilewska@imn.lukasiewicz.gov.pl (K.B.) \\ * Correspondence: patrycja.pokora@pwr.edu.pl
}

\section{check for} updates

Citation: Wojcieszak, D.; Mazur, M.; Pokora, P.; Wrona, A.; Bilewska, K.;

Kijaszek, W.; Kotwica, T.; Posadowski, W.; Domaradzki, J. Properties of Metallic and Oxide Thin Films Based on Ti and Co Prepared by Magnetron Sputtering from Sintered Targets with Different Co-Content. Materials 2021, 14, 3797. https://doi.org/10.3390/ ma14143797

Academic Editor: Alberto Vertova

Received: 1 May 2021

Accepted: 5 July 2021

Published: 7 July 2021

Publisher's Note: MDPI stays neutra with regard to jurisdictional claims in published maps and institutional affiliations.

Copyright: (C) 2021 by the authors. Licensee MDPI, Basel, Switzerland. This article is an open access article distributed under the terms and conditions of the Creative Commons Attribution (CC BY) license (https:// creativecommons.org/licenses/by/ $4.0 /)$

\begin{abstract}
In this work, selected properties of metallic and oxide thin films based on titanium and cobalt were described. Thin-film coatings were prepared using the magnetron sputtering method. The deposition was carried out from sintered targets with different Co-content $(2$ at. $\%, 12$ at. $\%$ and 50 at.\%). The relation between the Ti-Co target composition and the Co-content in the metallic and oxide films was examined. There was $15-20 \%$ more cobalt in the films than in the target. Moreover, the deposition rate under neutral conditions (in Ar plasma) was even 10-times higher compared to oxidizing Ar: $\mathrm{O}_{2}$ (70:30) plasma. A comprehensive analysis of the structural properties (performed with GIXRD and SEM) revealed the amorphous nature of (Ti,Co)Ox coatings, regardless of the cobalt content in the coating. The fine-grained, homogenous microstructure was observed, where cracks and voids were identified only for films with high Co-content. Optical studies have shown that these films were well transparent $(60 \% \div 80 \%)$, and the amount of cobalt in the target from which they were sputtered had a significant impact on the decrease in the transparency level, the slight shift of the absorption edge position (from $279 \mathrm{~nm}$ to $289 \mathrm{~nm}$ ) as well as the decrease in their optical band gap energy (from $3.13 \mathrm{eV}$ to $1.71 \mathrm{eV}$ ). Electrical studies have shown that in (Ti,Co)Ox thin films, a unipolar memristive-like effect can be observed. The occurrence of such effects has not been reported so far in the case of $\mathrm{TiO}_{2}$ coatings with the addition of $\mathrm{Co}$.
\end{abstract}

Keywords: amorphous thin film; magnetron sputtering; titanium; cobalt; memristive-like effect; transparent electronics

\section{Introduction}

The progress in electronic components functionality is related to the development of, among others, a new type of multifunctional thin-film coatings that will combine the features and attributes of various materials. Among the materials currently used in optoelectronics, titanium dioxide is well recognized whose production technology is mastered and has a wide application area. It is a very good matrix due to high chemical, thermal and mechanical resistance. This wide band gap oxide (ca. $3 \mathrm{eV})$ is neutral to the environment and exhibits high transparency for light in a wide spectral range (320 nm-6000 nm), has a high refractive index (2.4-2.7), and exhibits high photocatalytic activity [1,2]. $\mathrm{TiO}_{2}$ is used in the construction of optical filters [3], in solar cells [4] and as an active layer in gas sensors [5]. The properties of such transition metal oxides as $\mathrm{TiO}_{2}$ can be modified by a proper selection of deposition parameters, post-process treatment (e.g., annealing) or doping. Many additives and admixtures are used to modify the properties of $\mathrm{TiO}_{2}$. Cobalt 
can also be included, but its influence on the properties of titanium dioxide is not yet well understood. There are no comprehensive studies on thin films based on titanium and cobalt (especially in the form of oxides) that limit the possibility of fully exploiting the potential that the combination of these two materials can offer. Cobalt and its oxides exhibit high stability (especially in the form of $\mathrm{CoO}$ and $\mathrm{Co}_{3} \mathrm{O}_{4}$ ) [6], as well as high photocatalytic activity [7] or ferromagnetic properties [8]. Oxides and metallic materials based on Co can be applied in spintronics [9], magneto-optical devices [10], in the construction of semiconductor sensors [11], electrochromic coatings [12] and heterogeneous catalysts [13]. Materials based on titanium and cobalt constitute a "new group" of materials whose properties have not been fully understood and used so far. Doping titanium dioxide with cobalt allows to modify a number of its properties, primarily: structural [14-21], optical [14-18,20,21], electrical [15,16,20,21] and magnetic [20]. These coatings have been of great interest due to the formation of dilute magnetic semiconductors (DMS), which is promising for the manufacturing of spintronic and magneto-optic devices [22-24]. Co-doped $\mathrm{TiO}_{2}$ is a ferromagnetic material at room temperature [25] that turns it into a promising material for magneto-resistive random-access memory (MRAM) [24].

The properties of doped coatings based on titanium and its oxides largely depend on the method of their preparation. Among the many methods and their use in the electronics industry, attention should be paid to magnetron sputtering. It requires the use of targets that are the source of the sputtered material over which the plasma is ignited. Unfortunately, due to the magnetic properties of cobalt, it closes the magnetic field, and it is difficult to ignite the plasma over a magnetron with such a target. A solution can be the use of thin Co targets or multicomponent targets such as Ti-Co. This paper presents studies of the structural, optical and electrical properties of thin ( $\mathrm{Ti}, \mathrm{Co}) \mathrm{Ox}$ coatings. They were obtained by magnetron sputtering, and the analysis of their properties was described from the stage of sintering Ti-Co targets (with different material compositions) using the SPS method. It was necessary to determine the relationship between the cobalt content in the target and its final amount in both the metallic and oxide films. The results of electrical measurements have shown that in ( $\mathrm{Ti}, \mathrm{Co}) \mathrm{Ox}$ thin films, a unipolar memristive-like effect can be observed. The occurrence of such effects has not been reported so far in the case of $\mathrm{TiO}_{2}$ coatings with the addition of Co. This means that materials based on titanium and cobalt oxides may be prospective for electronics, not only due to their well-known spintronic properties but also because of their memristive-like behavior.

\section{Experimental}

\subsection{Preparation of Targets and Thin Films}

Metallic and oxide thin films were prepared using the magnetron sputtering method. For the preparation, the Ti-Co targets with 2 at. $\%, 12$ at. $\%$ and 50 at. $\%$ of Co-content were used. The targets were prepared by spark plasma sintering method (SPS) with the aid of the system provided by the FCT GmbH company [26,27]. Targets were sintered at $1200{ }^{\circ} \mathrm{C}$ in a graphite matrix. They had a diameter of $30 \mathrm{~mm}$ and a thickness of $3 \mathrm{~mm}$. The material composition of the targets was determined by a JXA-8230 X-ray microanalyzer (JEOL) with wave and energy dispersion spectrometers (WDS and EDS). These targets were used for the preparation of metallic and oxide thin films ( $\mathrm{Ti}-\mathrm{Co}$ and (Ti,Co)Ox, respectively). Pre-cleaning of the surface of targets and substrates was applied (low-pressure plasma discharge in the chamber: AC supply, $\left.170 \mathrm{~W}, 1.2 \times 10^{-1} \mathrm{mbar}, 3 \mathrm{~min}\right)$. Deposition processes were carried out using either pure Ar or a mixture of $\mathrm{Ar}: \mathrm{O}_{2}$ (70:30) as a working and reactive gas. The constant gas flow was set during the entire deposition process at $26 \mathrm{sccm}$ that was controlled by the ERG1MPSc unit (BetaERG). Films, as deposited in the argon atmosphere, were metallic, while the addition of $30 \%$ of oxygen was sufficient to obtain the full oxidation of the coatings. The pressure in a vacuum chamber during the process was $1.5 \times 10^{-2}$ mbar. The magnetron was powered by an MSS2 $(2 \mathrm{~kW})$ pulsed DC power supply unit (DORA Power System). The deposition process lasted 60 min for metallic and $120 \mathrm{~min}$ for oxide thin films. The substrates were placed on a rotating drum at a 
$100 \mathrm{~mm}$ distance from the sputtered target. Sputtering rate (SR) was calculated taking into consideration the film thickness and the time of material deposition on the given substrate holder area, which is sputtering time divided into 6. Films were deposited on fused silica $\left(\mathrm{SiO}_{2}\right)$ and silicon wafers.

\subsection{Methods of Targets and Thin Film Characterization}

The thickness and surface topography of as-deposited thin films was determined by the optical profiler Talysurf CCI (Taylor Hobson, Leicester, UK). Based on three-dimensional profiles, the analysis of surface roughness was performed, and the value of root mean square roughness $(\mathrm{Sq})$ was determined.

Surface observation and material composition of the metallic coatings was determined by a JXA-8230 (JEOL) X-ray microanalyzer equipped with WDS and EDS spectrometers. In the case of oxide ( $\mathrm{Ti}, \mathrm{Co}) \mathrm{Ox}$ films, the observations of surface and cross-section morphology were performed with the use of FEI Helios NanoLab 600i SEM coupled with an EDS spectrometer. Comparison of the intensity of $\operatorname{CoK} \alpha$ and $\operatorname{TiK} \alpha$ emission lines allowed to determine the amount of each element.

The structure of the oxide coatings was determined using X-ray diffraction in grazing incidence mode (GIXRD) with the aid of Empyrean PIXel3D (Panalytical, Malvern, UK) diffractometer with $\mathrm{Cu} \mathrm{K} \alpha$ radiation $(0.15406 \mathrm{~nm})$. The X-ray source was powered with $40 \mathrm{kV}$ and $30 \mathrm{~mA}$. The diffraction patterns were collected with the step size equal to $0.05^{\circ}$ in the 2 theta range of $20^{\circ}-80^{\circ}$ and time per step equal to $2 \mathrm{~s}$. The incidence angle was constant and equal to $3^{\circ}$ to the sample surface. For data analysis, MDI JADE 5.0 software (ICDD, Newtown Square, PA, USA) was used.

The optical properties of oxide coatings were analyzed based on transmission characteristics. Measurements were conducted in the wavelength range of 250-900 nm using Ocean Optics QE65000 spectrophotometer (Ocean Optics, Largo, FL, USA) and a coupled deuterium-halogen light source. The analysis carried out based on the obtained data allowed to determine the cut-off wavelength $\left(\lambda_{\text {cut-off }}\right)$ and optical band gap energy $\left(E_{g}{ }^{o p t}\right)$.

Electrical properties were determined based on the DC current-to-voltage electrical measurements using a Keithley SCS4200 semiconductor characterization system (Keithley Instruments LLC, Cleveland, OH, USA) and an M100 probe station (Cascade Microtech, Beaverton, OR, USA). The setup for the measurement of the capacitance-voltage characteristics was also additionally equipped with an Agilent 4294A precision impedance analyzer (Agilent Technologies Inc., Santa Clara, CA, USA) To allow electrical tests, circular gold $1 \mathrm{~mm}$ pads were evaporated at the top of the $(\mathrm{Ti}, \mathrm{Co}) \mathrm{Ox}$ thin film deposited on the silicon substrate. Measurements of $\mathrm{C}-\mathrm{V}$ characteristics were performed for 100 equally repeated cycles.

\section{Results and Discussion}

Thin-film coatings based on $\mathrm{Ti}$ and $\mathrm{Co}$ can have a wide application area in electronic and optoelectronic devices. As mentioned, especially transparent oxide coatings based on Ti-Co oxides can be used in many different areas. However, defining their properties (currently very poorly understood and described in the literature) requires reproducible mass-scale manufacturing, which can be provided by, e.g., magnetron sputtering. In this paper, first, the influence of the working gas atmosphere (neutral-Ar and oxidizing Ar: $\mathrm{O}_{2}$ ) in which Ti-Co targets were sputtered on the properties of the prepared coatings is discussed. The effect of Co-content in the target on the deposition rate was investigated. The next part is devoted to the analysis of a very broad characterization of the structural, optical and electrical properties of oxide $(\mathrm{Ti}, \mathrm{Co}) \mathrm{Ox}$ coatings in relation to their potential areas of application in electronics and optoelectronics. 


\subsection{Influence of Ti-Co Target Composition on Its Sputtering Conditions \\ 3.1.1. Material Composition of Sintered Ti-Co Targets}

In Figure 1, the microstructure with a WDS-map of the elemental distribution of the targets is shown. It was found that the Co-content in the three prepared targets was ca. 2 at. $\%, 12$ at. $\%$ and 50 at.\% (the exact numbers are collected in Table 1). The distribution of the elements in the $\mathrm{Ti}_{0.98} \mathrm{Co}_{0.02}$ target indicates that cobalt is dissolved in titanium in the entire volume of the target (Figure $1 \mathrm{a}$ ). Cobalt content in the $\mathrm{Ti}_{0.98} \mathrm{Co}_{0.02}$ target is slightly different from the assumed one (1.7 at.\%). This may be related due to the accuracy of the method or the effect of material segregation in the volume of the entire target. In the case of the $\mathrm{Ti}_{0.88} \mathrm{Co}_{0.12}$ target, high segregation of elements can be macroscopically observed. In the center of the $\mathrm{Ti}_{0.88} \mathrm{Co}_{0.12}$ target, the presence of a bright area of the Ti-Co phase and black ones of titanium are observed-most probably due to low cobalt dissolution (Figure 1b). The results of the WDS analysis of the $\mathrm{Ti}_{0.50} \mathrm{Co}_{0.50}$ target suggest a finely divided structure with visible dark areas which are richer in titanium (Figure 1c).

a)

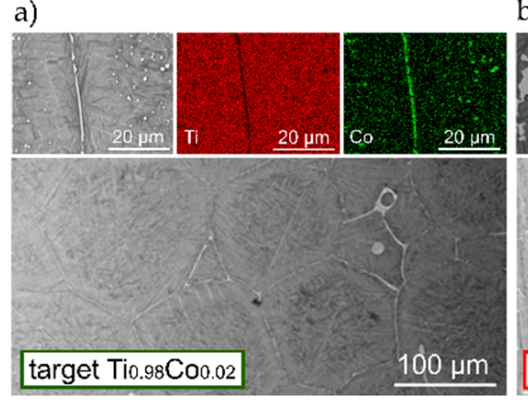

b)

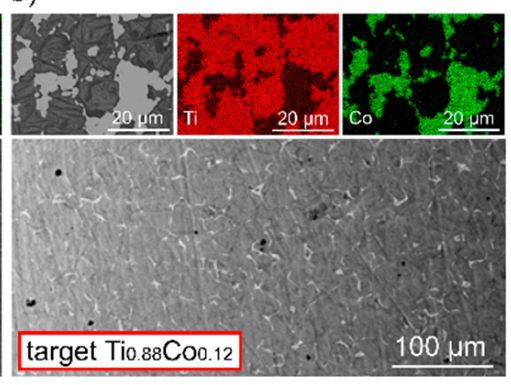

c)

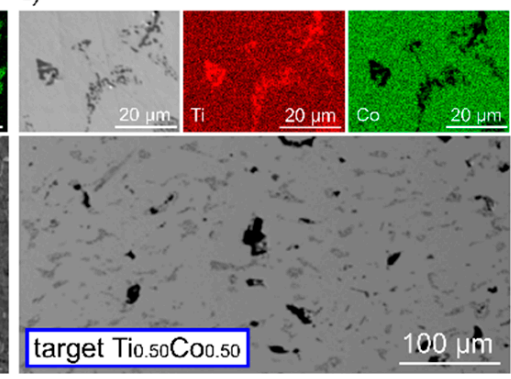

Figure 1. Microstructure with WDS maps of elemental distribution of $\mathrm{Ti}$ and $\mathrm{Co}$ in sintered targets: (a) $\mathrm{Ti}_{0.98} \mathrm{Co}_{0.02}$, (b) $\mathrm{Ti}_{0.88} \mathrm{Co}_{0.12}$, (c) $\mathrm{Ti}_{0.50} \mathrm{Co}_{0.50}$.

\subsubsection{Material Composition of Metallic Ti-Co Thin Films}

In Figure 2, images of surface topography with marked areas of EDS analysis for metallic Ti-Co thin films as deposited from $\mathrm{Ti}_{0.98} \mathrm{Co}_{0.02}, \mathrm{Ti}_{0.88} \mathrm{Co}_{0.12}$ and $\mathrm{Ti}_{0.50} \mathrm{Co}_{0.50}$ targets are shown.

Based on these results, a diagram of the relation between Co-content in the target and in the metallic film is shown in Figure 2d. The EDS results (obtained for five randomly selected areas on each sample) showed that the distribution of cobalt in the metallic films was homogeneous. It was also found that the Co-amount in the films was relatively $20 \%$ higher than in the targets. Detailed results of the material composition research of metallic coatings are summarized in Table 1.

\subsubsection{Material Composition of Oxide (Ti,Co)Ox Thin Films}

In Figure 3, the SEM images of surface topography with EDS maps of elemental distribution for oxide (Ti,Co)Ox thin films as deposited from $\mathrm{Ti}_{0.98} \mathrm{Co}_{0.02}, \mathrm{Ti}_{0.88} \mathrm{Co}_{0.12}$ and $\mathrm{Ti}_{0.50} \mathrm{Co}_{0.50}$ targets are shown. These results were used to draw up a diagram (Figure $3 \mathrm{~d}$ ) showing the relationship between the composition of the target and the oxide film. EDS maps of Ti, $\mathrm{O}$ and $\mathrm{Co}$ indicate a homogeneous distribution of these elements and a lack of agglomeration effects. The absence of areas with a clearly higher concentration of titanium or cobalt is important. This proves the good quality of sintered targets and the possibility of manufacturing coatings with a homogeneous composition based on them. Moreover, it was found that in the oxide films, there was more Co compared to its content in the target. The factor of 1.15 can be used to estimate the cobalt content of oxide coatings made from sintered Ti-Co targets. The 50 at.\% amount of cobalt also causes stresses in the structure, which results in the presence of nano cracks in the microstructure of the ( $\mathrm{Ti}, \mathrm{Co}) \mathrm{Ox}$ film (Figure 3c). Detailed results of EDS analysis are collected in Table 1. 
a)

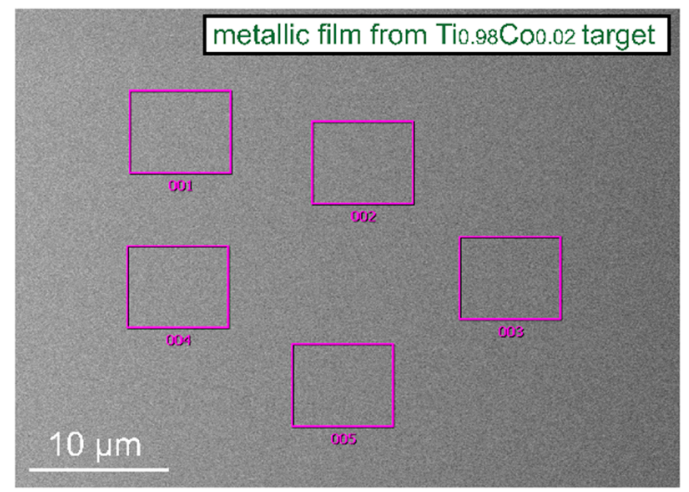

c)

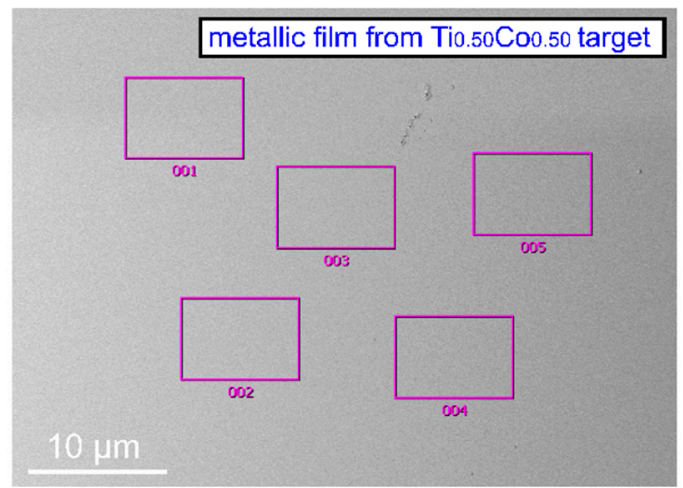

b)

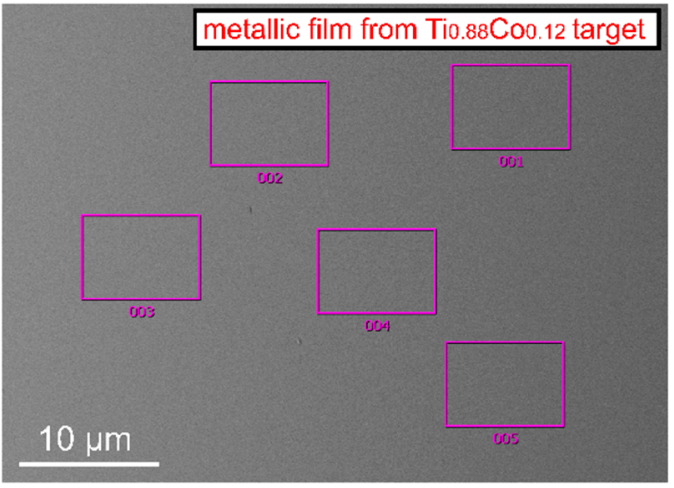

d)

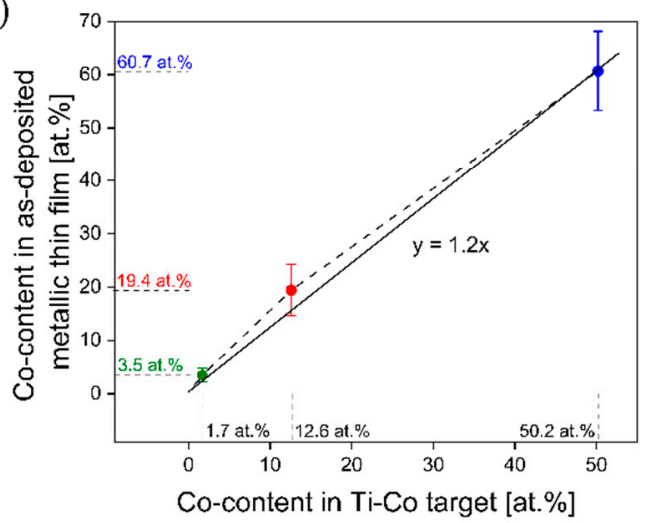

Figure 2. Images of surface topography with marked areas of EDS analysis for metallic Ti-Co thin films as deposited from: (a) $\mathrm{Ti}_{0.98} \mathrm{Co}_{0.02}$, (b) $\mathrm{Ti}_{0.88} \mathrm{Co}_{0.12}$, (c) $\mathrm{Ti}_{0.50} \mathrm{Co}_{0.50}$ targets; with (d) a diagram of the dependence between Co-content in the target and in the metallic film.
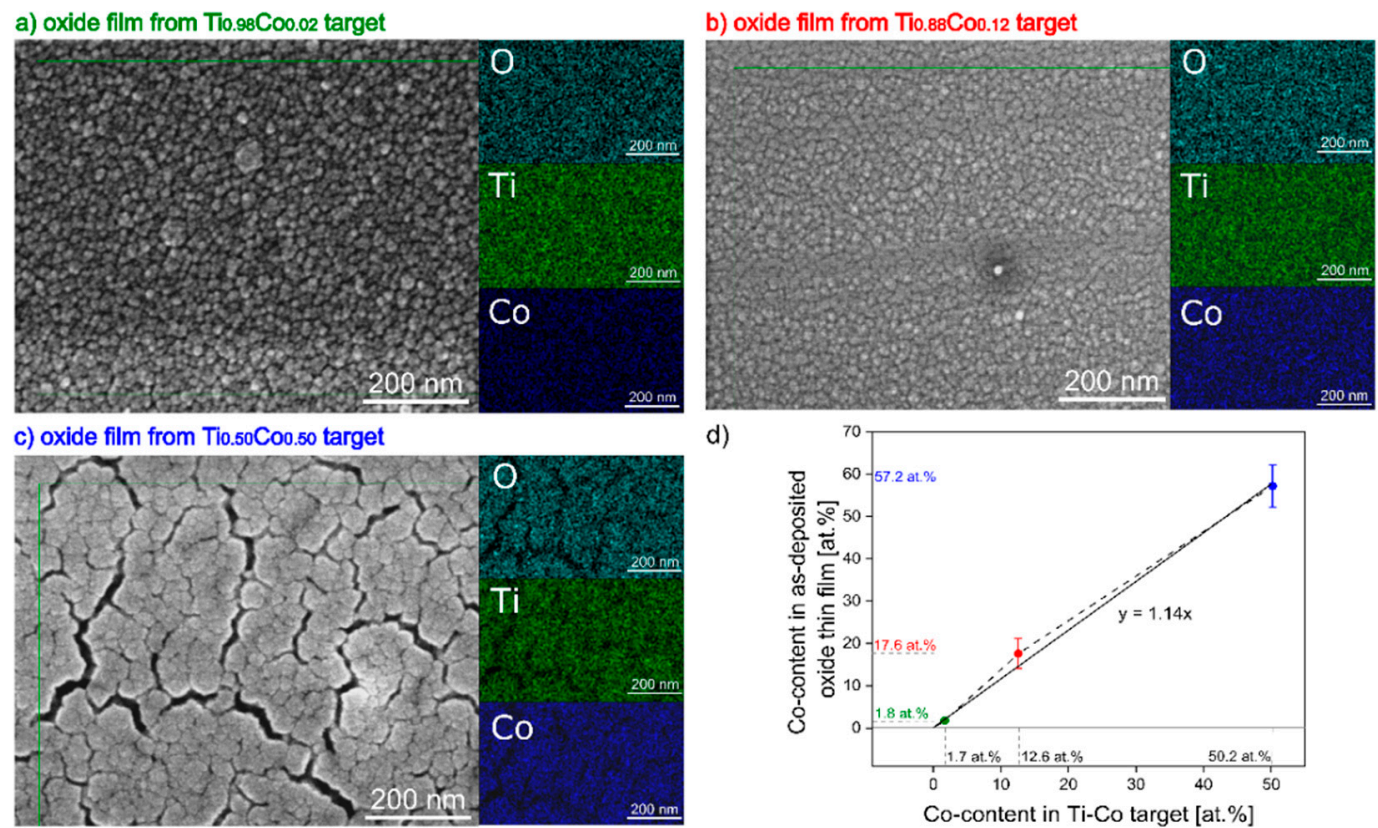

d)

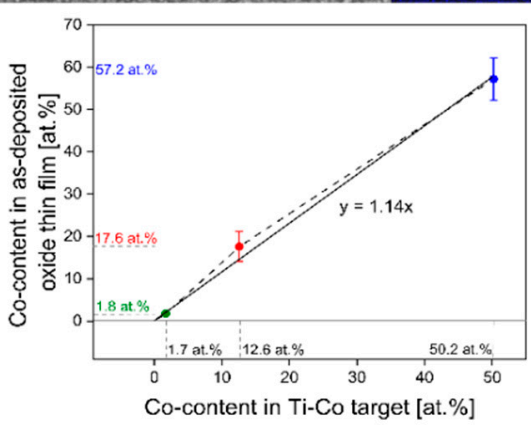

Figure 3. SEM images of surface topography with EDS maps of elemental distribution for oxide (Ti,Co)Ox thin films as deposited from: (a) $\mathrm{Ti}_{0.98} \mathrm{Co}_{0.02}$, (b) $\mathrm{Ti}_{0.88} \mathrm{Co}_{0.12}$, (c) $\mathrm{Ti}_{0.50} \mathrm{Co}_{0.50}$ targets; with (d) a diagram of the dependence between $\mathrm{Co}$-content in the target and in the oxide film. 
The relationship between the composition of Ti-Co targets and the content of cobalt in as-deposited metallic and oxide films can also be analyzed based on the detailed data, which are collected in Table 1 . As can be seen, there was relatively $15 \% \div 20 \%$ more cobalt in the films. These differences result from the sputtering yield of $\mathrm{Co}$ and Ti. In the case of oxide and metallic coatings deposited from the $\mathrm{Ti}_{0.88} \mathrm{Co}_{0.12}$ target, these differences are the greatest. However, it can be assumed that they result rather from the segregation of the titanium and cobalt atoms that were obtained with this target composition (see Figure 1b).

Table 1. Material composition of thin-film coatings (metallic and oxide) based on Ti and Co and targets used for their deposition by magnetron sputtering.

\begin{tabular}{cccc}
\hline \multirow{2}{*}{ Target } & \multicolumn{3}{c}{ Co-Content [at.\%] } \\
\cline { 2 - 4 } & \multirow{2}{*}{ In the Target } & \multicolumn{2}{c}{ In the Film } \\
\cline { 2 - 4 } & & Metallic (Ti-Co) & Oxide (Ti,Co)Ox \\
\hline $\mathrm{Ti}_{0.98} \mathrm{Co}_{0.02}$ & 1.7 & 19.5 & 1.8 \\
$\mathrm{Ti}_{0.88} \mathrm{Co}_{0.12}$ & 12.6 & 60.7 & 17.6 \\
$\mathrm{Ti}_{0.50} \mathrm{Co}_{0.50}$ & 50.2 & 57.2 \\
\hline
\end{tabular}

\subsubsection{Roughness of Metallic Ti-Co and Oxide (Ti,Co)Ox Thin Films}

The influence of target composition on its sputtering rate under argon-as an inert atmosphere as well as in Ar: $\mathrm{O}_{2}$ gas mixture (with $30 \%$ of oxygen) - as an oxidizing atmosphere was also studied with the aid of an optical profilometer. Figure 4 shows the three-dimensional surface profiles of metallic Ti-Co and oxide (Ti,Co)Ox coatings. As it can be seen, all prepared films were smooth and homogenous. A detailed analysis, based on the Sq parameter (the root mean square height of the surface), showed that the roughness was at the level of $1 \mathrm{~nm} \pm 0.2 \mathrm{~nm}$ (Figure 5). However, metallic films are characterized by almost the same Sq value $(0.9 \mathrm{~nm})$, which can also be concluded based on their 3D profiles (almost identical). In the case of oxide (Ti,Co)Ox films, the values of Sq parameter are also very similar, although slight differences in surface topography can be observed on the 3D profiles.

\subsubsection{Sputtering Rate of T-Co Targets for Metallic and Oxide Films}

Besides the roughness analysis, optical profilometry was also used for the determination of the film thickness. In the case of metallic Ti-Co films, the thickness was $324 \mathrm{~nm}$, $310 \mathrm{~nm}$ and $460 \mathrm{~nm}$ (for $60 \mathrm{~min}$ of sputtering) for $\mathrm{Ti}_{0.98} \mathrm{Co}_{0.02}, \mathrm{Ti}_{0.88} \mathrm{Co}_{0.12}$ and $\mathrm{Ti}_{0.50} \mathrm{Co}_{0.50}$, respectively. The thickness of the oxide (Ti,Co)Ox films was $65 \mathrm{~nm}, 70 \mathrm{~nm}$ and $236 \mathrm{~nm}$ (for 120 min of sputtering), respectively. These results were in good agreement with SEM cross-section observations. Taking into account the deposition time of each coating and the construction of the substrate holder (drum with six sides), the sputtering rate was determined (Figure 6).

A common conclusion for all coatings is the fact that an increase in the amount of cobalt in the target causes an increase in its sputtering rate and thus the deposition rate of both metallic and oxide coatings. In the case of the $\mathrm{Ti}_{0.98} \mathrm{Co}_{0.02}$ and $\mathrm{Ti}_{0.88} \mathrm{Co}_{0.12}$ targets, the $S R$ values are about 10-times higher in the argon itself than in the argon-oxygen gas mixture and are around $5 \AA /$ min and $50 \AA /$ min, respectively. For a higher cobalt content of the target, i.e., 50 at.\%, the sputtering rate was approximately $20 \AA / \mathrm{min}$ and $75 \AA / \mathrm{min}$ in the Ar and $\mathrm{Ar}: \mathrm{O}_{2}$ atmosphere, respectively. This proves that the use of an oxidizing atmosphere most likely causes the target poisoning effect and reduces its sputtering efficiency [28-30]. 


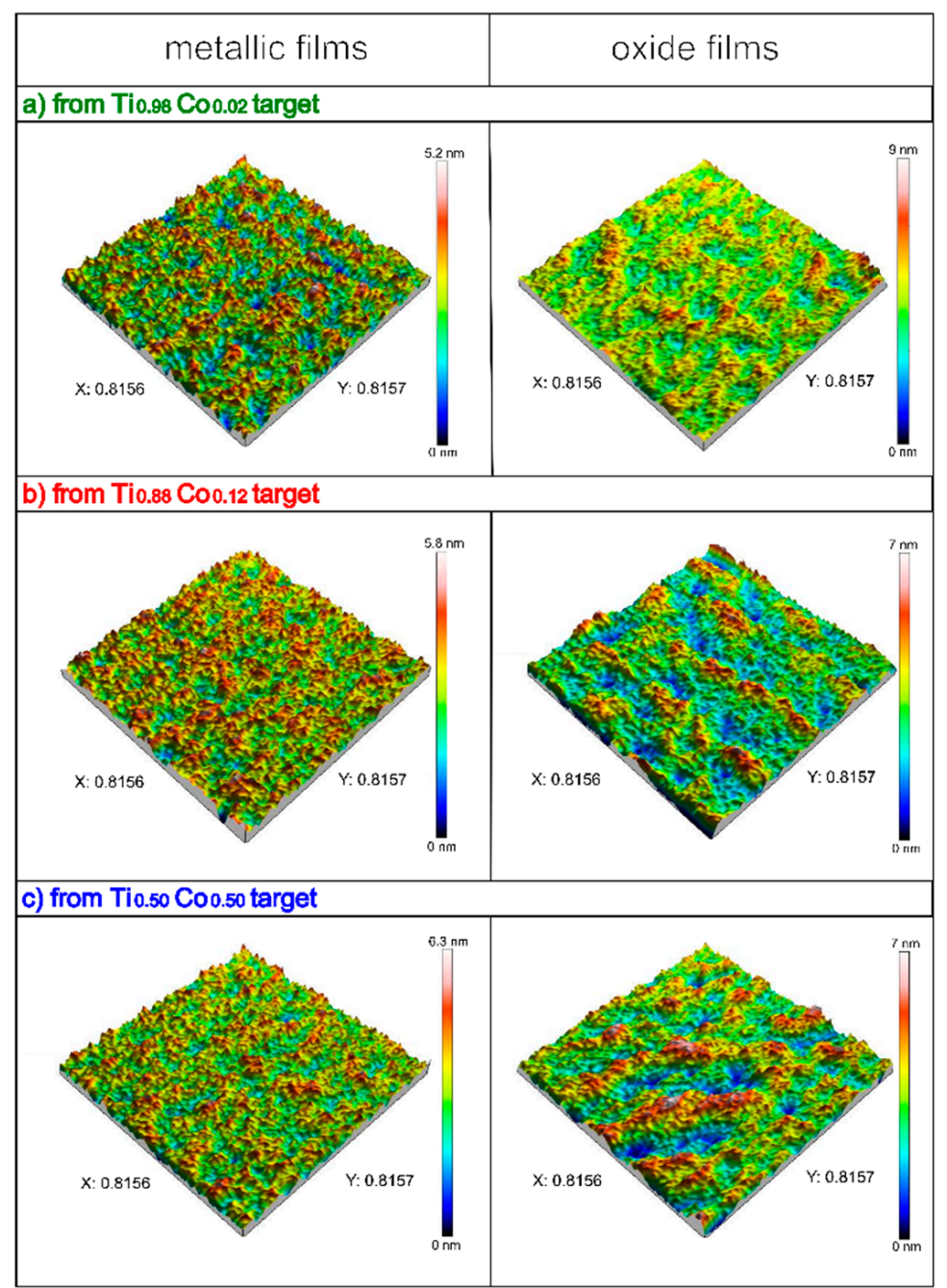

Figure 4. Three-dimensional profiles of metallic Ti-Co and oxide (Ti,Co)Ox thin films prepared by magnetron sputtering from different targets.

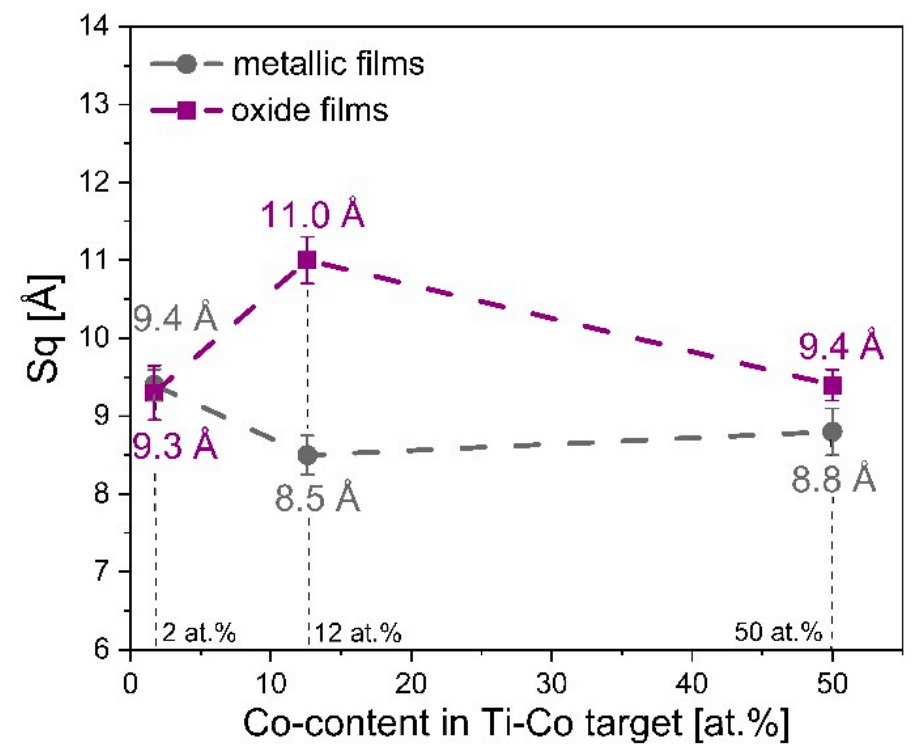

Figure 5. The influence of the Co-content in the Ti-Co target on the roughness of metallic and oxide thin films. Designation: Sq-root mean square roughness. 


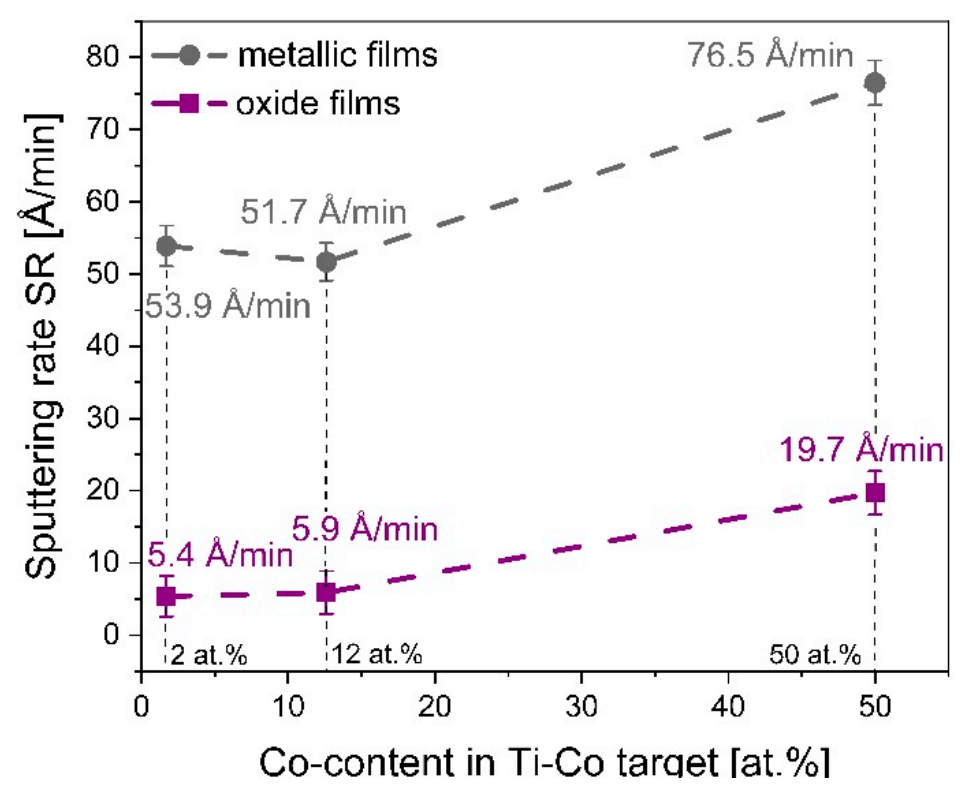

Figure 6. The influence of the Co-content in the Ti-Co target on the sputtering rate (SR) for metallic and oxide thin films.

\subsection{Structural, Optical and Electrical Characterization of (Ti,Co)Ox Thin Films}

\subsubsection{Structure of Oxide (Ti,Co)Ox Coatings}

The influence of material composition (Co-content) on the structure of the as-deposited oxide coatings was examined by GIXRD. In Figure 7, the diffraction patterns of (Ti,Co)Ox films are shown. As it can be seen, their amorphous nature was identified. Only a background boost related to the amorphous $\mathrm{SiO}_{2}$ substrate can be observed in the $2 \theta$ range of ca. $20 \div 35$. It should be emphasized that even for very thin coatings, their crystalline nature would be identified in grazing incidence measurements (GIXRD). In the case of pure titanium-based oxide coatings that were previously manufactured under the same conditions (described by the authors elsewhere [31,32]), a well-crystallized anatase structure (composed of crystallites with an average size less than $10 \mathrm{~nm}$ ) was observed. This means that the addition of cobalt, both in small and large quantities, causes the amorphization of thin films and prevents crystallization. Similar results were obtained by Bohoroquez et al. [33] or Quiroz et al. [24], where Co-doped $\mathrm{TiO}_{2}$ films prepared by DC magnetron sputtering were completely amorphous. The presence of such crystalline phases as $\mathrm{CO}_{3} \mathrm{O}_{4}, \mathrm{Ti}_{4} \mathrm{O}_{7}, \mathrm{CoTiO}_{3}$ and $\mathrm{CoTi}_{2} \mathrm{O}_{5}$ usually requires additional annealing at high temperatures (above $450{ }^{\circ} \mathrm{C}$ ). However, there are reports where the inclusion of such ions with lower valence states, as $\mathrm{Co}^{2+}$ and $\mathrm{Co}^{3+}$ increases the crystallization of $\mathrm{TiO}_{2}$ as well as the anatase to rutile transition [34]. The examined ( $\mathrm{Ti}, \mathrm{Co}) \mathrm{Ox}$ thin films were sputtered in $\mathrm{Ar}: \mathrm{O}_{2}$ (70:30) plasma. Such an atmosphere is rich in oxygen enough to obtain fully oxidized $\mathrm{TiO}_{2}$ films, while the formation of cobalt oxides (also well-crystallized) requires a higher portion of oxygen during the sputtering process [35]. Besides, low Co-content may also favor the growth of $\mathrm{TiO}_{2}$ :Co, permitting the diluted formation [24,35]. In our opinion, cobalt ions block the process of crystallite nucleation and prevent further ordering that resulted in the amorphous nature of the obtained films. 


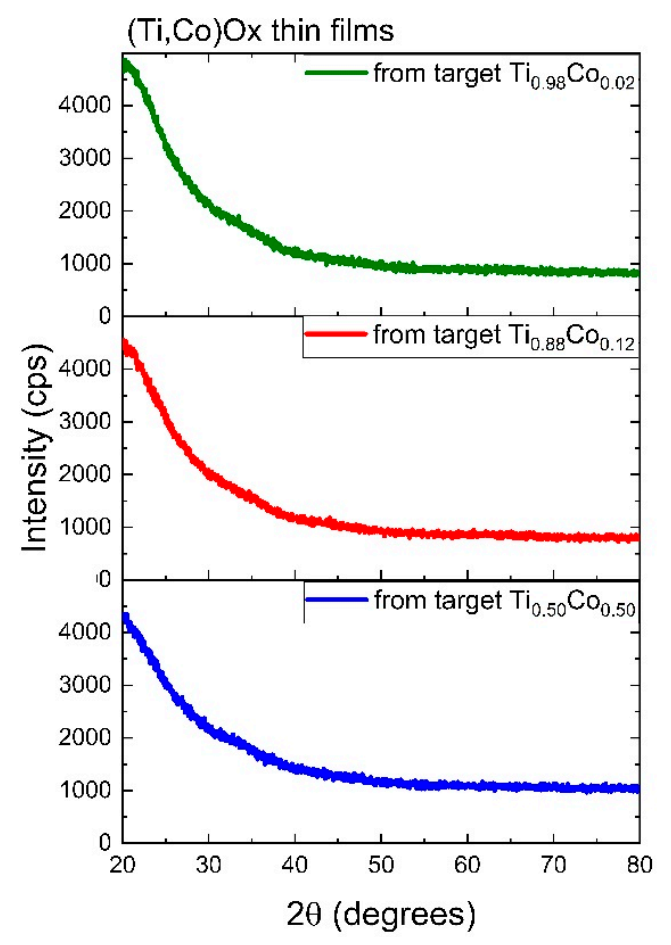

Figure 7. GIXRD patterns of oxide (Ti,Co)Ox thin films as deposited from different targets.

\subsubsection{Microstructure and Morphology of Oxide (Ti,Co)Ox Coatings}

The influence of the cobalt content on the structural properties of the oxide coatings was also investigated with the aid of SEM. For cross-section imaging, a $100 \mathrm{~nm}$ thick $\mathrm{Au}$ thin film was evaporated on the top of $\mathrm{TiO}_{2}$ :Co coatings to minimize the charging effect during SEM investigation and to obtain high-resolution images. Images of the surface topography (Figure 8), as well as cross-sections (Figure 9), revealed a densely packed columnar structure of all films. In particular, as the amount of cobalt in the films increases, the width of the columns increases (on average from $20 \mathrm{~nm}$ to $50 \mathrm{~nm}$ ). A similar effect can be observed on the surface, which was built from the tops of densely arranged columns. An increase in their diameter is related to the increase in Co-content. Moreover, in the case of films sputtered from targets with 2 at. $\%$ and 12 at.\% of $\mathrm{Co}$, their microstructure is free of cracks or voids between columns, which can be seen in the case of the film obtained from the $\mathrm{Ti}_{0.50} \mathrm{Co}_{0.50}$ target. Based on SEM images, the deposition in the so-called "T zone" or "transition zone" can be identified, which is characterized by the presence of very small and elongated grains due to the superficial diffusion contribution to the species mobility among grains [36]. The characters of the nucleation process, associated with the substrate temperature and deposition method, indicate the random distribution of cobalt ions in the $\mathrm{TiO}_{2}$ matrix. Such conclusions were also reached in the work of Quiroz et al. [24]. Moreover, other works in the literature on $\mathrm{TiO}_{2}: \mathrm{Co}$ also indicate the effect of fine crystallinity of the grains caused by the addition of cobalt $[33,37]$.

\subsubsection{Optical Properties of Oxide (Ti,Co)Ox Coatings}

The characterization of the optical properties of $(\mathrm{Ti}, \mathrm{Co}) \mathrm{Ox}$ coatings was performed on the basis of light transmission characteristics (Figure 10). It was found that all films exhibit high transparency. The value of $\mathrm{T}_{\lambda=550 \mathrm{~nm}}$ was ca. $75 \%$ for coatings deposited from $\mathrm{Ti}_{0.98} \mathrm{Co}_{0.02}$ and $\mathrm{Ti}_{0.88} \mathrm{Co}_{0.12}$ targets. However, 50 at. $\%$ of $\mathrm{Co}$ in the target resulted in the manufacturing of less transparent film, with transparency close to $60 \%$. It is noteworthy that the oxide films based on titanium and cobalt are often characterized by a very low level of light transmission [33], and only their additional annealing at a temperature above $500{ }^{\circ} \mathrm{C}$ allows to obtain high transparency (usually in the range of $60 \% \div 70 \%$ ). 


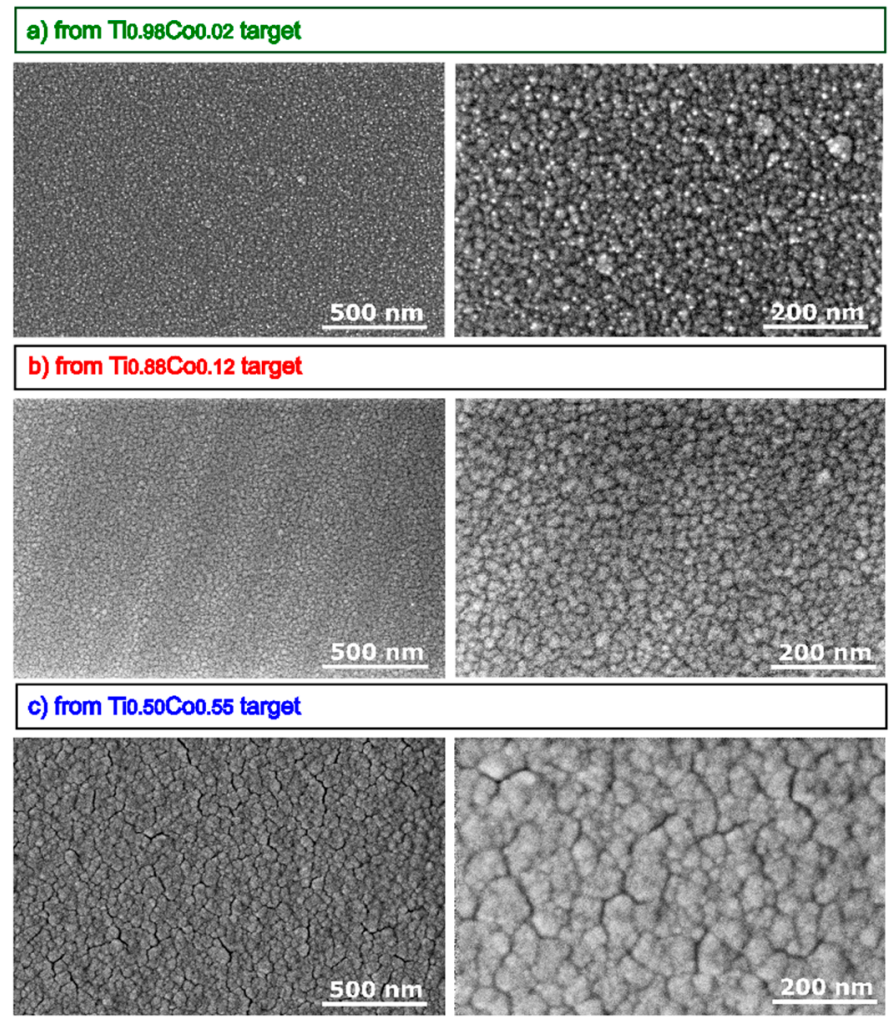

Figure 8. SEM images of surface of (Ti,Co)Ox thin films prepared from: (a) $\mathrm{Ti}_{0.98} \mathrm{Co}_{0.02}$, (b) $\mathrm{Ti}_{0.88} \mathrm{Co}_{0.12}$ (c) $\mathrm{Ti}_{0.50} \mathrm{Co}_{0.50}$ targets.

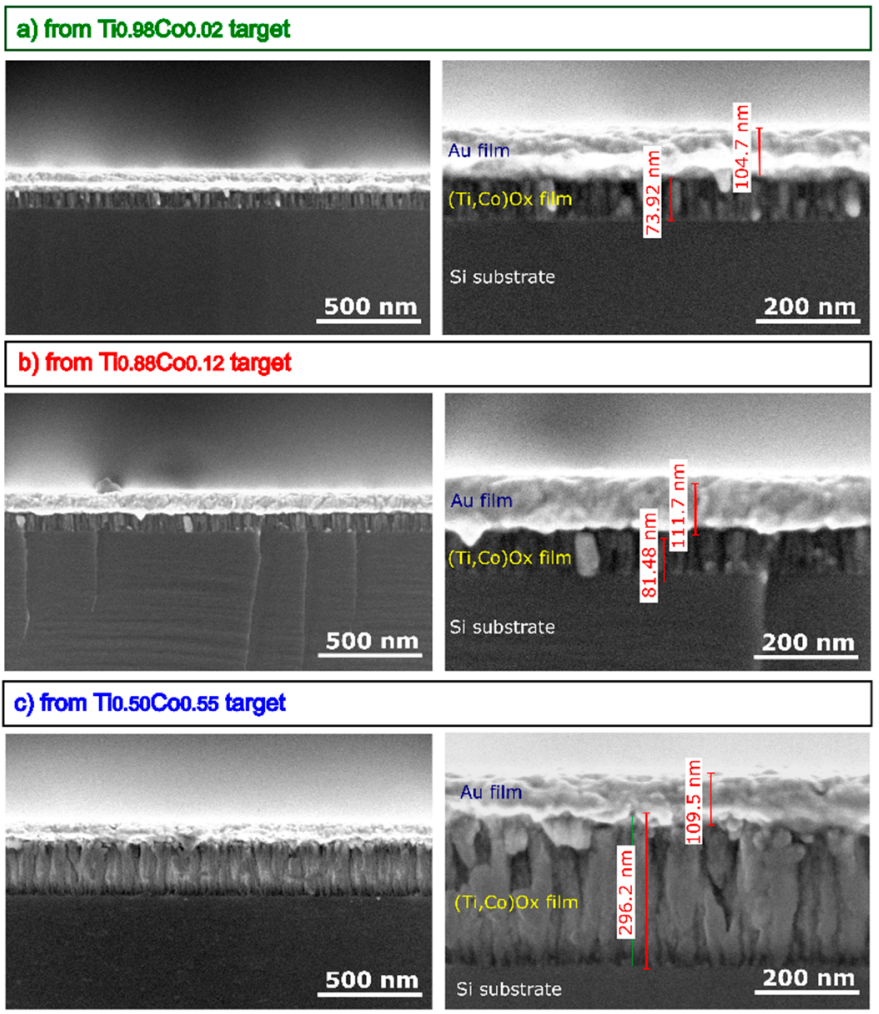

Figure 9. SEM images of cross-section of $(\mathrm{Ti}, \mathrm{Co}) \mathrm{Ox}$ thin films prepared from: (a) $\mathrm{Ti}_{0.98} \mathrm{Co}_{0.02}$, (b) $\mathrm{Ti}_{0.88} \mathrm{Co}_{0.12}$, (c) $\mathrm{Ti}_{0.50} \mathrm{Co}_{0.50}$ targets (with Au layer on top). 


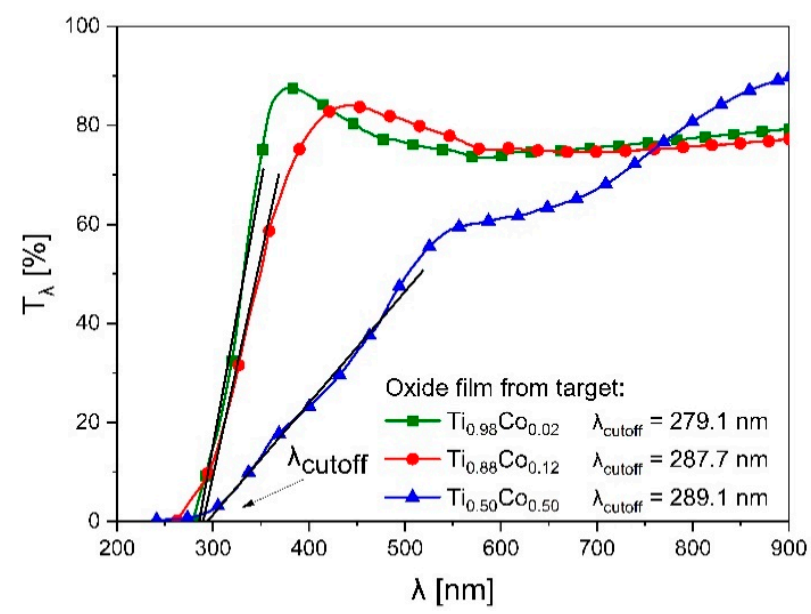

Figure 10. Transmission characteristics of $(\mathrm{Ti}, \mathrm{Co}) \mathrm{Ox}$ thin films prepared from different targets. Designations: $\mathrm{T}_{\lambda}$-light transmission coefficient, $\lambda_{\text {cutoff }}$-position of the optical absorption edge.

Based on the transmission characteristics, the Tauc plots (for indirect transitions) were determined, and the optical band gap ( $\mathrm{E}_{\mathrm{g}}{ }^{\mathrm{opt}}$ ) was estimated (Figure 11). As it can be seen, the value of $\mathrm{Eg}_{\mathrm{g}}{ }^{\mathrm{pt}}$ was equal to $3.13 \mathrm{eV}, 2.17 \mathrm{eV}$ and $1.71 \mathrm{eV}$ for the coatings as deposited from targets with 2 at. $\%, 12$ at. $\%$ and 50 at.\% of Co, respectively. This means that the greater the amount of cobalt in the (Ti,Co)Ox film, the lower the width of its optical band gap. Such effect was also noticed in other works [14,21]. In most cases, similar to the results described in this paper, an increase in the amount of cobalt causes a decrease in the $\mathrm{E}_{\mathrm{g}}{ }^{\text {opt }}$ value. Our results of $\mathrm{E}_{\mathrm{g}}{ }^{\mathrm{opt}}$ were also presented as a function of the amount of cobalt in the target (Figure 12). They were compared with the values of the position of the optical absorption edge $\left(\lambda_{\text {cutoff }}\right)$. In this case, the effect of Co-content was also observed as a so-called "red shift" (towards longer wavelengths of light). Such effect was also reported in other works. For example, Subramanian et al. [18] or Musa et al. [20] in transparent $\mathrm{TiO}_{2}$ :Co films also obtained a shift of $\lambda_{\text {cutoff }}$ towards longer wavelengths due to a large amount of cobalt. It should be noted that the position of the optical absorption edge is mostly determined by the manufacturing technique and the process parameters. Therefore, the "blue shift" of the $\lambda_{\text {cutoff }}$ can also be found [15].

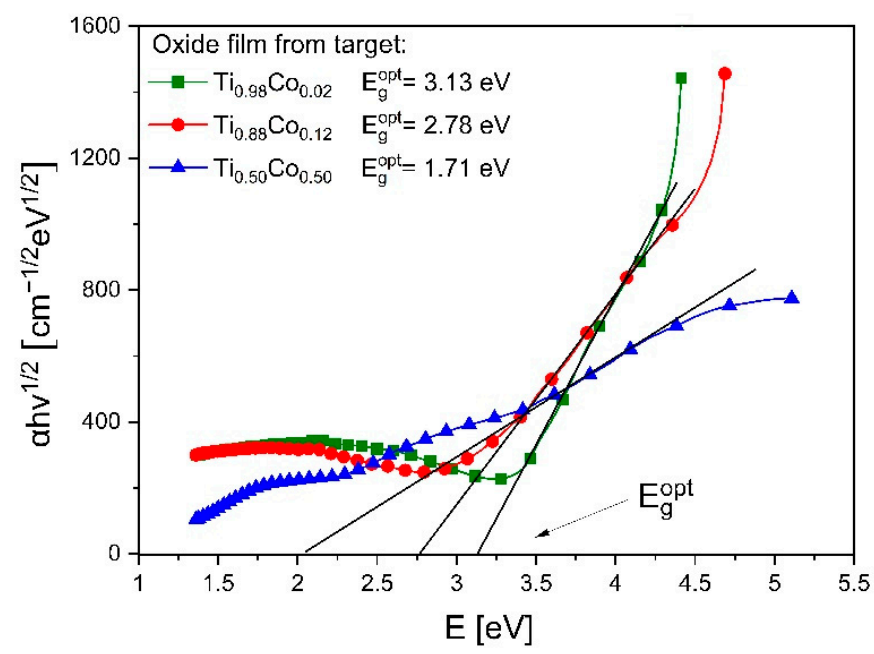

Figure 11. Tauc plots for (Ti,Co)Ox thin films prepared from different targets. Designations: $\mathrm{E}_{\mathrm{g}}$ opt optical band gap. 


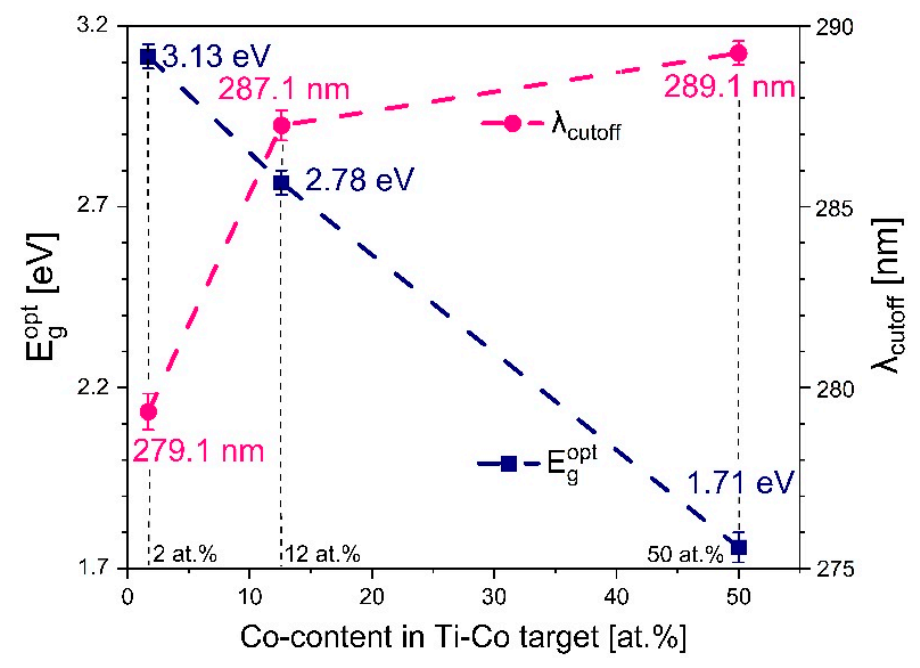

Figure 12. Influence of Co-content in the Ti-Co target on the optical band gap ( $\left.\mathrm{E}_{\mathrm{g}}{ }^{\mathrm{opt}}\right)$ and position of the optical absorption edge $\left(\lambda_{\text {cutoff }}\right)$ of $(\mathrm{Ti}, \mathrm{Co}) \mathrm{Ox}$ thin films.

\subsubsection{Electrical Properties of Oxide ( $\mathrm{Ti}, \mathrm{Co}) \mathrm{Ox}$ Coatings}

An investigation of electrical properties was performed for the prepared $(\mathrm{Ti}, \mathrm{Co}) \mathrm{Ox}$ thin films deposited on (p-type) silicon substrates. Additionally, a circular gold pad with $3 \mathrm{~mm}$ in diameter was deposited on the surface of the thin films to allow electrical measurements $(\mathrm{Au} /(\mathrm{TiCo}) \mathrm{Ox} / \mathrm{Si})$. That makes possible the discussion on the perspective application of prepared thin films in microelectronics. In Figure 13, the I-V characteristics measured in the transverse configuration are presented. I-V characteristics were presented in a conventional manner; the positive voltage/current values are due to the forward bias condition of the prepared structure, whereas negative values are due to the reverse bias condition.

During the measurements, the current was forced from negative to positive values and then back from the applied positive current values to the negative ones while the voltage drop was sensed using the source-measure unit (current-driven measurement). Sweeping the current allowed to observe the hysteresis loops, and as one can see in Figure 13a-c, but the shape of each of the measured curves is distinct. In the case of the structures with ( $\mathrm{Ti}, \mathrm{Co}) \mathrm{Ox}$ thin films containing lower Co concentration, a unipolar memristive-like effect can be observed, which is manifested by the memory loop with forward bias polarization (Figure 13a) [38,39]. The occurrence of such effects has not been reported so far in the case of $\mathrm{TiO}_{2}$ coatings with the addition of $\mathrm{Co}$. Usually, for these types of thin-film materials, a linear relationship between current and voltage is usually observed $[15,20]$. This means that materials based on titanium and cobalt oxides may be prospective for electronics, not only because of their spintronic application but also because of their memristive-like behavior. As it can be seen in Figure 13a, increasing the current during the measurement did not result in the change of shape of the measured characteristics until ca. $1.25 \mathrm{~V}$. Above that voltage, the current suddenly increased in a relatively narrow voltage range $(1.25 \mathrm{~V} \div 1.5 \mathrm{~V})$. Changing the direction of the current flowing through the examined structure resulted in the formation of the hysteresis loop, indicating the occurrence of a memory effect. On the other hand, under the reverse bias condition, no hysteresis effect was observed, indicating the unipolar behavior of the observed phenomenon. A similar effect can be observed for the structure with $(\mathrm{Ti}, \mathrm{Co}) \mathrm{Ox}$ thin film containing about 17.6 at.\% of cobalt (Figure 13b), but the memory effect, in this case, is much less pronounced (much narrower hysteresis loop). Quite unexpected results of the I-V measurement can be observed in Figure 13c. Measurements performed in similar voltage/current conditions, in this case, resulted in a visible very wide nonpinched hysteresis loop. We believe that this result was connected with a much thicker (Ti,Co)Ox thin film containing 57.2 at.\% of $\mathrm{Co}$, which resulted in a longer distance for electrical charge carriers that were injected from/to the metal electrode through the entire cross-section of the thin film. In this case, the 
observed wide hysteresis loop results rather from the polarisation and relaxation processes that occur in the thin oxide film and "charging" the structure upon switching the direction of the current flowing through it.

a)
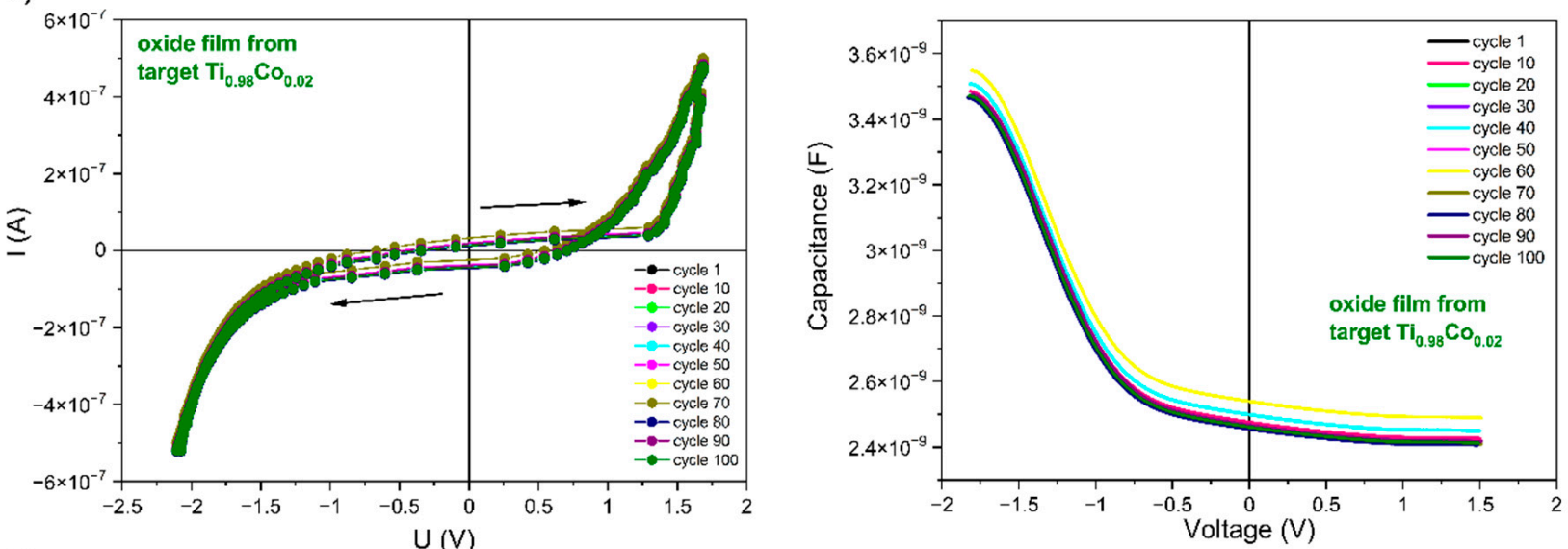

b)
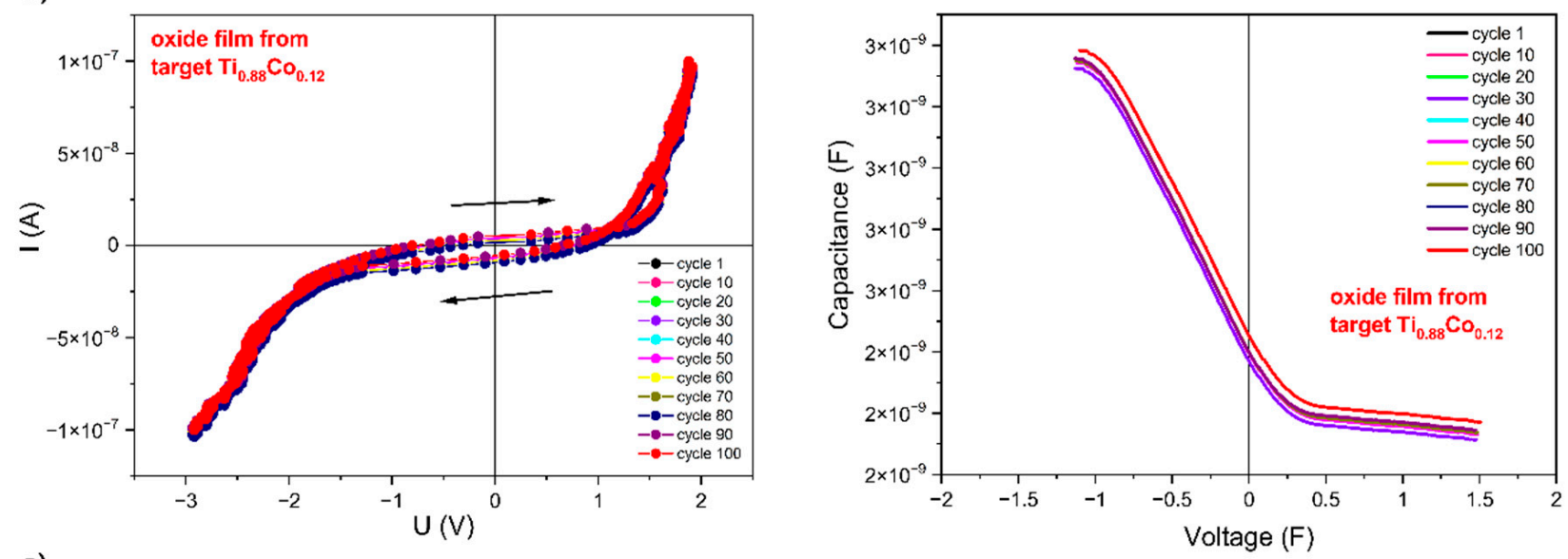

c)
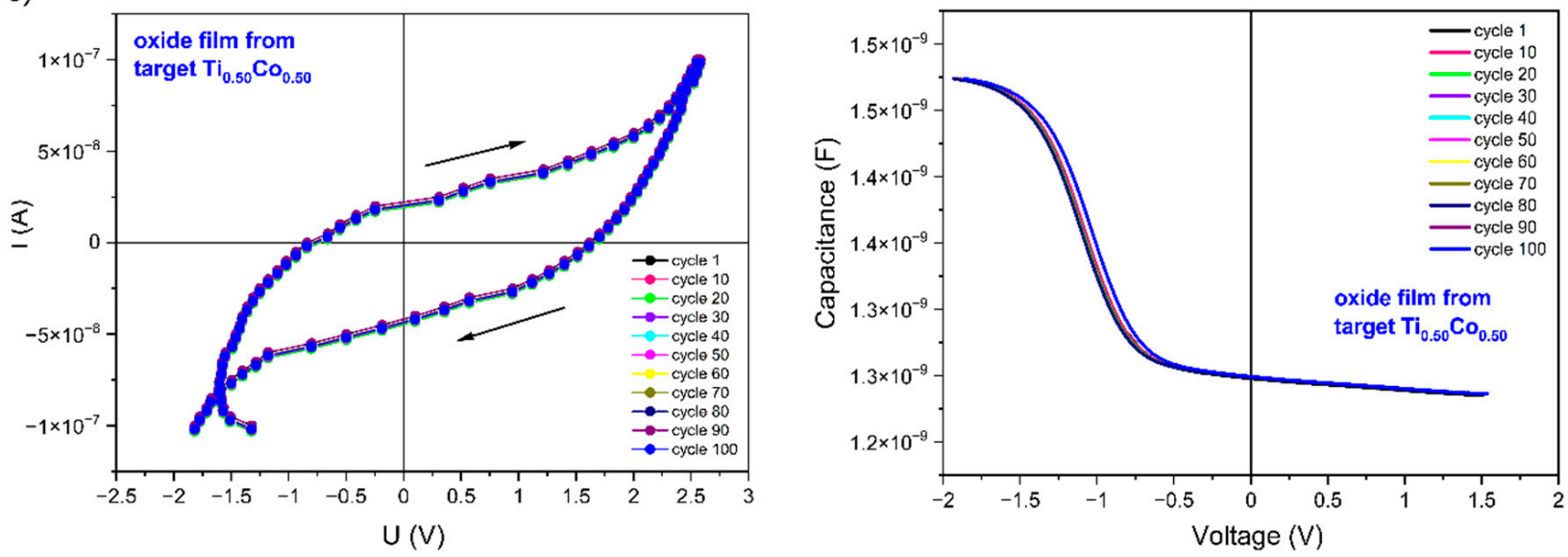

Figure 13. Current to voltage (I-V) and capacitance to voltage (C-V) characteristics of prepared $\mathrm{Au} /(\mathrm{Ti}, \mathrm{Co}) \mathrm{Ox} / \mathrm{Si}$ structures with different cobalt concentration-prepared from: (a) $\mathrm{Ti}_{0.98} \mathrm{Co}_{0.02}$, (b) $\mathrm{Ti}_{0.88} \mathrm{Co}_{0.12}$, (c) $\mathrm{Ti}_{0.50} \mathrm{Co}_{0.50}$ targets.

The capacitance-to-voltage characteristics were measured by sweeping the voltage bias from $-2.0 \mathrm{~V}$ to $2.0 \mathrm{~V}$ using a $100 \mathrm{kHz}$ sinusoidal measuring signal. The measurement was performed in a parallel electrical equivalent circuit. All three measured $\mathrm{C}-\mathrm{V}$ curves showed a typical shape as for metal-oxide-semiconductor structures. The applied voltage sweeps the switching structure from accumulation to depletion state. Negative gate voltage 
at a forward bias condition causes the majority charge carriers (holes) in Si substrate to accumulate near the Si-oxide interface. Holes are injected from the Si substrate and are trapped in the oxide layer that results in a visible shift of the $\mathrm{C}-\mathrm{V}$ curve toward negative voltages. For positive gate voltages, the Si-oxide interface is depleted, and in this state, the electrons from the inversion layer are injected into the oxide. Measured capacitance (c.a. $1.5 \mathrm{nF}$ ) in the accumulation state (oxide capacitance) was about two times lower for the structure with the highest Co-concentration (Figure 13c) than for the two remaining devices with much lower Co-concentration (c.a. $2.9 \mathrm{nF}$ and $3.5 \mathrm{nF}$ ). This observation can be understood taking into account that the thickness of the thin film with the highest Co-concentration was more than two times higher. Measurements of current-voltage and capacitance-voltage characteristics performed for 100 equally repeated cycles testify to the high stability of the prepared thin-film structures. Additionally, retention plots for samples with switching behavior were constructed and presented in Figure 14. As one can see, in both cases, the maximum difference between $\mathrm{R}_{\mathrm{ON}}$ and $\mathrm{R}_{\mathrm{OFF}}$ resistance is quite similar.

a)

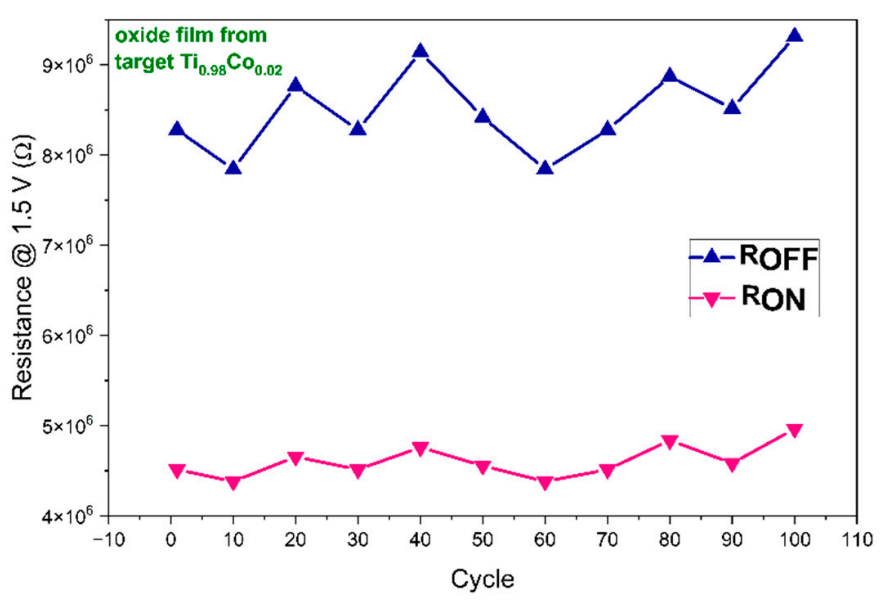

b)

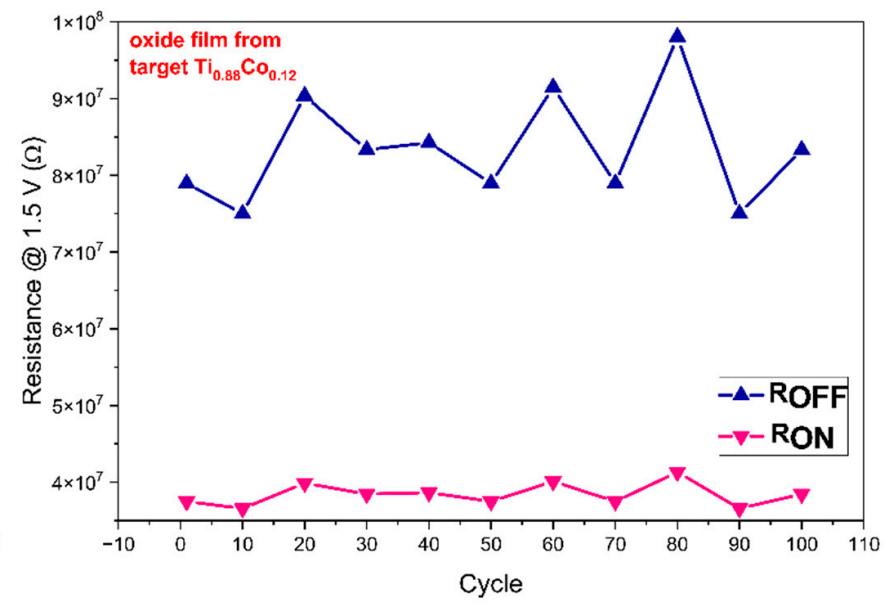

Figure 14. Retention plots of prepared $\mathrm{Au} /(\mathrm{Ti}, \mathrm{Co}) \mathrm{Ox} / \mathrm{Si}$ structures with different cobalt concentration-prepared from: (a) $\mathrm{Ti}_{0.98} \mathrm{Co}_{0.02}$ and (b) $\mathrm{Ti}_{0.88} \mathrm{Co}_{0.12}$ targets.

\section{Conclusions}

The obtained results showed that the magnetron sputtering method is successfully suitable for the repeatable manufacturing of metallic and oxide thin-film coatings based on titanium and cobalt. In the case of the above-mentioned films, the deposition processes were carried out from Ti-Co targets with 2 at.\%, 12 at.\% and 50 at.\% of cobalt. The relation between target composition and the Co-content in the metallic and oxide films was defined. There was relatively $15-20 \%$ more cobalt in the films than in the target. The deposition rate under neutral conditions (in Ar plasma) was much higher compared to oxidizing Ar: $\mathrm{O}_{2}$ plasma. GIXRD analysis of the structural properties revealed the amorphous nature of $(\mathrm{Ti}, \mathrm{Co}) \mathrm{Ox}$ coatings, regardless of the cobalt content in the coating. The fine-grained, homogenous microstructure was identified by SEM images, where cracks and voids were identified only for films with high Co-content. Optical studies have shown that as-deposited oxide films were well transparent $(60 \% \div 80 \%)$, and the Co-content had a significant impact on the transparency level decrease as well as on the "red shift" of the optical absorption edge and the decrease in $\mathrm{E}_{\mathrm{g}}{ }^{\mathrm{opt}}$ (from $3.13 \mathrm{eV}$ to $1.71 \mathrm{eV}$ ). Electrical studies revealed that in $(\mathrm{Ti}, \mathrm{Co}) \mathrm{Ox}$ thin films (with low cobalt content) deposited on $\mathrm{Si}$ substrate, a unipolar memristive-like effect can be observed. The occurrence of such effects has not been reported so far in the case of $\mathrm{TiO}_{2}$ coatings with the addition of Co. 
Author Contributions: Conceptualization, D.W., P.P. and J.D.; methodology, D.W., M.M., J.D. and A.W.; software, D.W., M.M., K.B., T.K. and J.D.; validation, D.W., P.P. and J.D.; formal analysis, D.W., M.M., P.P. and J.D.; investigation, D.W., M.M., P.P., A.W., K.B., W.K., T.K., W.P. and J.D.; resources, D.W., J.D. and A.W.; data curation D.W., P.P. and J.D.; writing-original draft preparation, D.W., P.P. and J.D.; writing-review and editing, D.W., P.P., W.P. and J.D.; visualization, D.W., M.M., P.P. and W.K.; supervision, D.W.; project administration, J.D.; funding acquisition, J.D. All authors have read and agreed to the published version of the manuscript.

Funding: This work was co-financed from the sources given by the Polish National Science Centre (NCN) as a research project number 2018/29/B/ST8/00548.

Institutional Review Board Statement: Not applicable.

Informed Consent Statement: Not applicable.

Data Availability Statement: The data presented in this study are available in this article.

Conflicts of Interest: The authors declare no conflict of interest.

\section{References}

1. Lin, C.-P.; Chen, H.; Nakaruk, A.; Koshy, P.; Sorrell, C.C. Effect of annealing temperature on the photocatalytic activity of TiO 2 thin films. Energy Procedia 2013, 34, 627. [CrossRef]

2. Mergel, D.; Buschendorf, D.; Eggert, S.; Grammes, R.; Samset, B. Density and refractive index of $\mathrm{TiO}_{2}$ films prepared by reactive evaporation. Thin Solid Film. 2000, 371, 218. [CrossRef]

3. Kitui, M.; Mwamburi, M.M.; Gaitho, F.; Maghanga, M. Optical Properties of $\mathrm{TiO}_{2}$ based multilayer thin films: Application to optical filters. Int. J. Thin Film. Sci. Technol. 2015, 4, 17. [CrossRef]

4. Elsaeedy, H.I.; Qasem, A.; Yakout, H.A.; Mahmoud, M. The pivotal role of TiO2 layer thickness in optimizing the performance of TiO2/P-Si solar cell. J. Alloy. Compd. 2021, 867, 159150. [CrossRef]

5. $\quad$ Lyson-Sypien, B.; Radecka, M.; Rekas, M.; Swierczek, K.; Michalow-Mauke, K.; Graule, T.; Zakrzewska, K. Grain-size-dependent gas-sensing properties of $\mathrm{TiO}_{2}$ nanomaterials. Sens. Actuators B Chem. 2015, 211, 67-76. [CrossRef]

6. Mei, J.; Liao, T.; Ayoko, G.A.; Bell, J.; Sun, Z. Cobalt oxide-based nanoarchitectures for electrochemical energy applications. Prog. Mater. Sci. 2019, 103, 596-677. [CrossRef]

7. Verma, M.; Mitan, M.; Kim, H.; Vaya, D. Efficient photocatalytic degradation of Malachite green dye using facilely synthesized cobalt oxide nanomaterials using citric acid and oleic acid. J. Phys. Chem. Solids 2021, 155, 110125. [CrossRef]

8. Gajbhiye, M.M.; Sharma, S.; Nigam, A.K.; Ningthoujam, R.S. Tuning of single to multi-domain behavior for monodispersed ferromagnetic cobalt nanoparticles. Chem. Phys. Lett. 2008, 466, 181-185. [CrossRef]

9. Kaloyeros, A.E.; Pan, Y.; Goff, J.; Arkles, B. Cobalt thin films: Trends in processing technologies and emerging applications. ECS J. Solid State Sci. Technol. 2019, 8, P119. [CrossRef]

10. Hirohata, A.; Yamada, K.; Nakatani, Y.; Prejbeanu, J.L.; Diényd, B.; Pirro, P.; Hillebrands, B. Review on spintronics: Principles and device applications. J. Magn. Magn. Mater. 2020, 509, 166711. [CrossRef]

11. Bewan, S.; Ndolomingo, N.J.; Meijboom, R.; Bingwa, N. Cobalt oxide promoted tin oxide catalysts for highly selective glycerol acetalization reaction. Inorg. Chem. Commun. 2021, 128, 108578. [CrossRef]

12. Švegl, F.; Orel, B.; Hutchins, M.G.; Kalcher, K. Structural and spectroelectrochemical investigations of sol-gel derived electrochromic spinel $\mathrm{Co}_{3} \mathrm{O}_{4}$ films. J. Electrochem. Soc. 1996, 143, 1532. [CrossRef]

13. Bahlawane, N.; Rivera, E.F.; Kohse-Höinghaus, K.; Brechling, A.; Kleineberg, U. Characterization and tests of planar $\mathrm{Co}_{3} \mathrm{O}_{4}$ model catalysts prepared by chemical vapor deposition. Appl. Catal. B Environ. 2004, 53, 245. [CrossRef]

14. Husain, S.; Alkhtaby, L.A.; Giorgetti, E.; Zoppi, A.; Maurizio Muniz, M. Influence of cobalt doping on the structural, optical and luminescence properties of sol-gel derived $\mathrm{TiO}_{2}$ nanoparticles. Philos. Mag. 2017, 97, 17. [CrossRef]

15. Bhat, S.; Sandeep, K.M.; Kumar, P.; Dharmaprakash, S.M.; Byrappa, K. Characterization of transparent semiconducting cobalt doped titanium dioxide thin films prepared by sol-gel process. J. Mater. Sci. Mater. Electron. 2018, 29, 1098-1110. [CrossRef]

16. Jiang, P.; Xiang, W.; Kuang, J.; Liu, W.; Cao, W. Effect of cobalt doping on the electronic, optical and photocatalytic properties of $\mathrm{TiO}_{2}$. Solid State Sci. 2015, 46, 27-32. [CrossRef]

17. Park, Y.R.; Kim, K.J. Structural and optical properties of rutile and anatase $\mathrm{TiO}_{2}$ thin films: Effects of Co doping. Thin Solid Film. 2005, 484, 24. [CrossRef]

18. Subramanian, M.; Vijayalakshmi, S.; Venkataraj, S.; Jayavel, R. Effect of cobalt doping on the structural and optical properties of $\mathrm{TiO}_{2}$ films prepared by sol-gel process. Thin Solid Film. 2008, 516, 3776. [CrossRef]

19. Miao, Y.; Zhai, Z.; Jiang, L.; Shi, Y.; Yana, Y.; Duan, D.; Zhen, K.; Wang, J. Facile and new synthesis of cobalt doped mesoporous $\mathrm{TiO}_{2}$ with high visible-light performance. Powder Technol. 2014, 266, 365-371. [CrossRef] 
20. Musa, M.Z.; Ameran, Z.F.; Mamat, M.H.; Malek, M.F.; Rasheid, N.A.; Noor, U.M.; Rusop, M. Effects of cobalt doping concentration on the structural, electrical, and optical properties of titanium dioxide thin films. In Proceedings of the Institute of Electronics Engineers, 2011 International Conference on Electronic Devices, Systems and Applications (ICEDSA), Mid Valley City, Malaysia, 25-27 April 2011. [CrossRef]

21. Islam, N.M.; Podder, J. The role of $\mathrm{Al}$ and Co co-doping on the band gap tuning of $\mathrm{TiO}_{2}$ thin films for applications in photovoltaic and optoelectronic devices. Mater. Sci. Semicond. Process. 2021, 121, 105419. [CrossRef]

22. Huo-ping, Z.; Nan-nan, X.; Gong-ping, L.; Tian-jing, L.; Xing-xin, G.; Jing-sheng, C. The magnetic properties and microscopic structural of a ferromagnetic semiconductor: Rutile $\mathrm{TIO}_{2}$ single crystals implanted with cobalt ions. Surf. Coat. Technol. 2013, 229, 109-111. [CrossRef]

23. Ganshina, E.A.; Granovsky, A.B.; Orlov, A.F.; Perov, N.S.; Vashuk, M.V. Magneto-optical spectroscopy of diluted magnetic oxides TiO2-8: Co. J. Magn. Magn. Mater. 2009, 321, 723-725. [CrossRef]

24. Quiroz, H.P.; Galíndez, E.F.; Dussan, A. Ferromagnetic-like behavior of Co doped $\mathrm{TiO}_{2}$ flexible thin films fabricated via cosputtering for spintronic applications. Heliyon 2020, 6, e03338. [CrossRef] [PubMed]

25. Yu, H.; Ni, L.; Wang, Y. Non-Volatile In-Memory Computing by Spintronics; Morgan \& Claypool Publishers: Williston, VT, USA, 2017; pp. 13-14.

26. Lei, C.; Du, Y.; Zhu, M.; Huo, W.; Wu, H.; Zhang, Y. Microstructure and mechanical properties of in situ TiC/Ti composites with a laminated structure synthesized by spark plasma sintering. Mater. Sci. Eng. A 2021, 812, 141136. [CrossRef]

27. Wimler, D.; Lindemann, J.; Gammer, C.; Spoerk-Erdely, P.; Stark, A.; Clemens, H.; Mayer, S. Novel intermetallic-reinforced near- $\alpha$ Ti alloys manufactured by spark plasma sintering. Mater. Sci. Eng. A 2020, 792, 139798. [CrossRef]

28. Depla, D.; De Gryse, R. Target poisoning during reactive magnetron sputtering: Part I: The influence of ion implantation. Surf. Coat. Technol. 2004, 183, 184-189. [CrossRef]

29. Waite, M.M.; Ismat Shah, S.I. Target poisoning during reactive sputtering of silicon with oxygen and nitrogen. Mater. Sci. Eng. B 2007, 140, 64-68. [CrossRef]

30. Arif, M.; Eisenmenger-Sittner, C. In situ assessment of target poisoning evolution in magnetron sputtering. Surf. Coat. Technol. 2017, 324, 345-352. [CrossRef]

31. Wiatrowski, A.; Mazur, M.; Obstarczyk, A.; Kaczmarek, D.; Pastuszek, R.; Wojcieszak, D.; Grobelny, M.; Kalisz, M. Influence of magnetron powering mode on various properties of $\mathrm{TiO}_{2}$ thin films. Mater. Sci. Pol. 2018, 36, 748-760. [CrossRef]

32. Wiatrowski, A.; Mazur, M.; Obstarczyk, A.; Wojcieszak, D.; Kaczmarek, D.; Morgiel, J.; Gibson, D. Comparison of the physicochemical properties of $\mathrm{TiO}_{2}$ thin films obtained by magnetron sputtering with continuous and pulsed gas flow. Coatings 2018, 8, 412. [CrossRef]

33. Bohórquez, A.J.; Quiroz, H.P.; Dussan, A. Growth and crystallization of Cobalt-doped $\mathrm{TiO}_{2}$ alloys: Effect of substrate and annealing temperature. Appl. Surf. Sci. 2019, 474, 97. [CrossRef]

34. Rao, C.N.R.; Subba Rao, G.V. Transition Metal Oxides-Crystal Chemistry, Phase Transition and Related Aspects; 1974 U.S. Department of Commerce, Michigan, National Bureau of Standards. Available online: http:/ / refhub.elsevier.com/S2405-8440(20)30183-3 / sref26 (accessed on 1 March 2021).

35. NIST Laboratory. Co Oxides Structure; 2019. Available online: https://srdata.nist.gov/xps/main_search_menu.aspx (accessed on 15 February 2021).

36. Thornton, J.A. Structure-zone models of thin films. Model. Opt. Thin Film. 1988, 0821. [CrossRef]

37. Quiroz, H.P.; Dussan, A. Synthesis temperature dependence on magnetic properties of cobalt doped $\mathrm{TiO}_{2}$ thin films for spintronic applications. Appl. Surf. Sci. 2019, 484, 688-691. [CrossRef]

38. Domaradzki, J.; Wojcieszak, D.; Kotwica, T.; Mańkowska, E. Memristors: A short review on fundamentals, structures, materials and applications. Int. J. Electron. Telecommun. 2020, 66, 373-381. [CrossRef]

39. Domaradzki, J.; Kotwica, T.; Mazur, M.; Kaczmarek, D.; Wojcieszak, D. Memristive properties of transparent oxide semiconducting (Ti,Cu)Ox-gradient thin film. Semicond. Sci. Technol. 2018, 33, 015002. [CrossRef] 